\title{
Improvement of diagnostics and monitoring in the heat-supplying organizations in the complex of ecological management of urban development
}

\author{
Natalia Verstina ${ }^{1, *}$, Tatiana Tereshkina ${ }^{2}$, and Evgeny Evseev ${ }^{3}$ \\ ${ }^{1}$ Moscow State University of Civil Engineering, Yaroslavskoye Shosse, 26, 129337, Moscow, Russia \\ ${ }^{2}$ Saint Petersburg State University of Industrial Technologies and Design, Bolshaya Morskaya street, \\ 18, 191186, Saint-Petersburg, Russia \\ ${ }^{3}$ Moscow Institute of Physics and Technology, Institutskiy per., 9, Dolgoprudny, 141701, Moscow \\ Region, Russia
}

\begin{abstract}
The directions of the improvement of diagnostics and monitoring processes in the heat-supplying organizations in the conditions of modern urban development are considered in the article. Conditions of obtaining information in the system of monitoring based on various methods of diagnostics of heating systems, taking into account their technical condition, which provide accounting of ecological aspects in management along with traditional maintenance parameters of engineering systems are systematized. The matters of improvement of information quality as the bases for adoption of managerial decisions in the system of ecological management, allowing developing multiple scenarios of development of the heat-supplying organizations taking into account ecological priorities, are considered. The directions of further development of diagnostics and monitoring in the heatsupplying organizations by the means of integration with the system of ecological management, focused on ensuring ecological safety of the heating systems maintenance are defined.
\end{abstract}

\section{Introduction}

The developments of cities, which number constantly grows, bring new realities, which are often expressed in emergence of environmental problems, connected with urbanization. The matters of preservation of the resource potential are becoming more and more significant in the world practice. The stage of the final use of energy resources in the infrastructure of life support of the modern Russian cities is realized by the systems of heat supply, which have to provide quality of activity of the population in various climatic conditions, and $35 \%$ of all the final consumption of heating energy in the country are carried out through the systems of the centralized heat supply. Supply of consumers with heating energy on the basis of the principle of the centralized transportation of resources is also characteristic of some other countries $[1,2]$ including Denmark, Norway, Sweden, Finland, which are most representative on the European continent $[3,4,5]$, and Canada on the North American continent, which is similar in climatic conditions to the majority of the Russian territories.

* Corresponding author: Kosti4eva.daria@yandex.ru 
The system of the centralized heat supply of Russia, formed by the heat-supplying organizations (HSO) of various scale is the world's largest (it makes up more than $40 \%$ of the volume of the world centralized production and delivery of heating energy). In this regard the research of maintenance of such scale of engineering systems are indicative for identification of their impact on the environment in modern urban development, as well as for determining of the most progressive engineering and managerial decisions of perspective character. Being a component of the centralized heat supply system of the modern cities, the heating systems represent the difficult and dangerous engineering constructions, intended for transportation of heating energy from heat sources to consumers. Experts note that the feature of the Russian heat supply is the high saved-up wear of the equipment and rates of updating of heating systems which are not corresponding, that leads to the violations in the heating systems work, and that is followed by losses of heating energy and its adverse environmental impact. At the same time, there is the tendency to growth of environmental risks during the heating systems maintenance in the conditions of preservation of traditional approaches to ecological management as well as the lack of information, demanded for its improvement.

In this regard the development of methodical provisions on the improvement of diagnostics and monitoring of maintenance characteristics of the heating systems, designed in order to change significantly effectiveness of ecological management due to the increase in reliability of transportation of heat in combination with the growth of profitability and ecological safety of their maintenance in the conditions of urban development, becomes more and more relevant.

\section{Methods}

Considering the matter of the improvement of diagnostics and monitoring of operational characteristics of heating systems in the context of ecological management, it is possible to point out the important starting aspect of ensuring its efficiency, connected with the realization scientifical-and-technological priorities of the development of the heat supply branch of the Russian Federation [6].

Firstly, there is the need of improvement of quality of information as the bases of managerial decisions of all the levels in HSO, which is provided by diagnostics and monitoring, for the choice of optimum main, auxiliary and additional technologies during designing, construction and maintenance of heating systems, taking into account the use of the best available technologies and guarantees of ecological safety is indisputable. In relation to heating systems ecological safety can be considered as the difficult complex property of its object, its subsystems, technical means, etc., which is demonstrated though the ability not to break the quality of the natural (natural) and anthropogenic (artificial) environment and also to eliminate and reduce to minimum the negative consequences of the impact on the condition of natural balance in all environments of the functioning. Ecological safety has to be formed during designing, to be implemented in the course of construction, to be provided during maintenance, to be restored during repair and to be improved during modernization.

Secondly, the use of modern technologies for obtaining the data on operational characteristics of heating systems during diagnostics and monitoring, as well as the formation of scientifically based estimates of the condition of engineering systems and the environmental risks, connected with it, will allow to carry out the reorganization of established practices of management of HSO in this field of activity of the organization in the direction of transition:

- from "historically developed approaches" to the reasonable system decisions, harmonized with the development priorities;

- from actions for elimination of ecological negative impacts to the acceptance of precautionary measures for their prevention. 
Concretizing these provisions we will note that the factor of providing information in the system of monitoring of the required quality, and first of all primary character of information - about actual state of engineering systems - in many respects is determined by the use of the technical means and technologies of diagnostics which are the basis of methods of diagnostics of technical condition of heating systems. We treat the diagnostics method as the set of actions, which are aimed on the solution of a certain task (the formation of primary character of information on technical condition of engineering system, such as data acquisition and way of their processing). Obtaining information, necessary for decisionmaking in ecological management, in the system of monitoring of modern HSO based on definite methods of diagnostics we have considered in a certain sequence in several stages:

- firstly we have identified the technical conditions of heating systems, characteristic of all the types of engineering systems it is not dependent on their constructive decisions. We have also analysed the character of the events leading to changes of technical states and the accompanying impacts on the environment and the reasons owing to which they are carried out. It is obvious that the methods of diagnostics, applied during the monitoring have to provide the opportunity both fixings of technical states, and definitions of the reasons which have occurred or the possible changes bearing environmental risks;

- the next matter is the definition of approaches to the choice of sites of the heating systems, which are the subject to diagnosing, allowing to receive relevant and necessary for decision-making in the system of ecological management of information which allows to build priorities in the application of methods of diagnostics of the condition of heating systems and to define the most problem from the point of view of existence of environmental risks of the part of heating systems economy of $\mathrm{HSO}$, requiring paramount attention;

- the final stage of the research is the representation forms in monitoring of information on technical conditions of heating systems, which have to be created by results of application of certain methods of diagnostics. The established practices differed so far in considerable variety of options, which more disoriented, than promoted decision-making in the system of ecological management based on forecasting of a condition of heating systems economy of HSO. As the perspective questions, evolving from the results of the conducted research the perspective of formation of all the range of methods of technical diagnostics of a condition of the heating systems, which are present at open sources and the choice from them the most answering the purpose of obtaining information of monitoring for improvement of management in HSO in the conditions of realization of scientific-and-technological and ecological priorities of the development of the heat supply branch is designated.

We will pass to more detailed consideration of the previously mentioned sequence. For the organization of monitoring it is important to clear the key concept, which plays a backbone role during obtaining and the analysis of information. That concept is "technical condition" of the heating system. In the drafted methodical provisions "technical condition" is understood to be the list of the quantitative and qualitative parameters of the operated engineering system, recorded at a given time in certain environmental conditions. According to GOST 27.002-89 it is offered to distinguish the following degrees of "technical condition" of the operated heating systems (heating systems under maintenance), which changes cause the deterioration in indicators of ecological safety of engineering systems [7]. Those changes have to be defined by the methods of diagnostics, applied during monitoring, and should be used within the organization of ecological management:

- properly functioning, when the heating system under maintenance conforms to all the obligatory and recommended requirements of the specifications and technical documents, regulating all the stages of the life cycle of engineering systems. The heating system is ecologically safe;

- faulty, when the heating system under maintenance does not conform at least to one obligatory requirement of the specifications and technical documents, regulating all the 
stages of the life cycle of engineering systems, that leads to emergence of environmental risks;

- operable, when the values of all the quantitative and qualitative parameters of the heating system under maintenance, characterizing the ability to perform the set functions, conform to mandatory requirements of the specifications and technical documents, that causes possibility of environmental risks;

- disabled, when the value of at least one quantitative or qualitative parameter of the heating system under maintenance, characterizing the ability to perform the set functions, does not conform to requirements of the specifications and technical documents. Causing damages of a certain type to the environment takes place;

- extreme, when there exits full discrepancy of the quantitative or qualitative parameters of the heating system, characterizing its ability to perform the set functions, to requirements of the specifications and technical documents. Causing damages of a certain type to the environment takes place. At the same time further use of heating system, according its destination is inadmissible or inexpedient.

Earlier the authors have carried out the detailed analysis of the interrelation of these conditions as well as the analysis of the possible reasons of their change, considering not only the maintenance stage, but also design stage and the stage of laying of the heating system [ 8 , $9,10,11]$. At the same time the interrelation of the observance of requirements of the specifications and technical documents for all the stages of the life cycle, defining final operational characteristics of the engineering systems has been established and estimated. Despite rather long term, which has passed from the moment of the initial research, the described situation, connected with the existence of risks of ecological damages, caused by the heating systems under maintenance in urban development significantly has not changed. [12]. It serves as a great argument for the search of new instruments of ecological management, including instruments, based on monitoring of operational characteristics of the heating systems. We concretize the technical conditions of the heating systems in relation to the problems of the conducted research, aimed at finding ways of formation of data for making managerial decisions within ecological management of various level.

\section{Results}

The analysis of ten-year statistics of damages of the high-level heating systems has been carried out, for the definition of the most characteristic causes, which need to be revealed by the methods of diagnostics of technical condition. The results are presented in Figure 1.

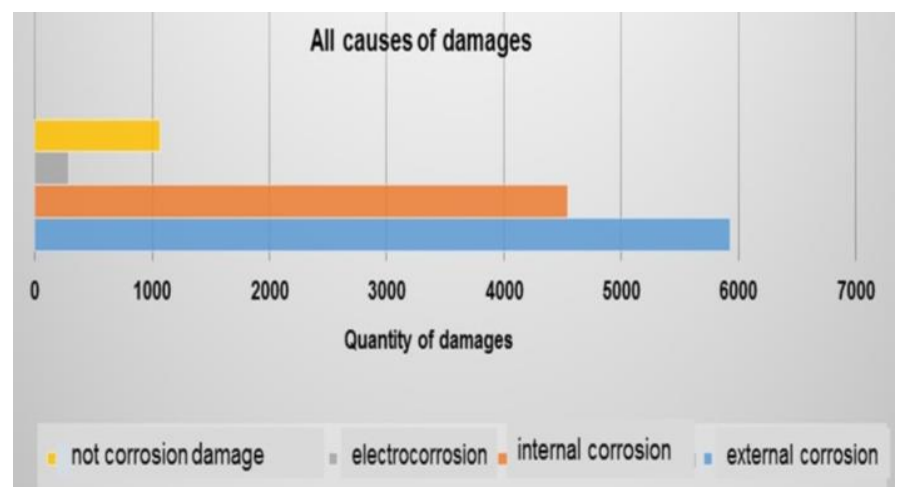

Fig. 1. Distribution of the causes of change of technical conditions of the heating systems according to the main types, which need to be revealed by the methods of diagnostics (control) during the monitoring. 
The provided data prove the well-known fact: the metal corrosion, which is localized both outside and in the pipeline, prevails among the causes of change of technical conditions of the heating systems and environmental risks in the Russian HSO. This cause has been detailed, depending on the constructive solutions of engineering systems, which, in turn, influence the choice of the methods of diagnostics during monitoring. At the same time the consequences of the changes of technical conditions of the heating systems (certain types of damages of structural elements, in this case metal ones, and even refusals in their work, connected with adverse environmental impact were analysed (Figure 2).

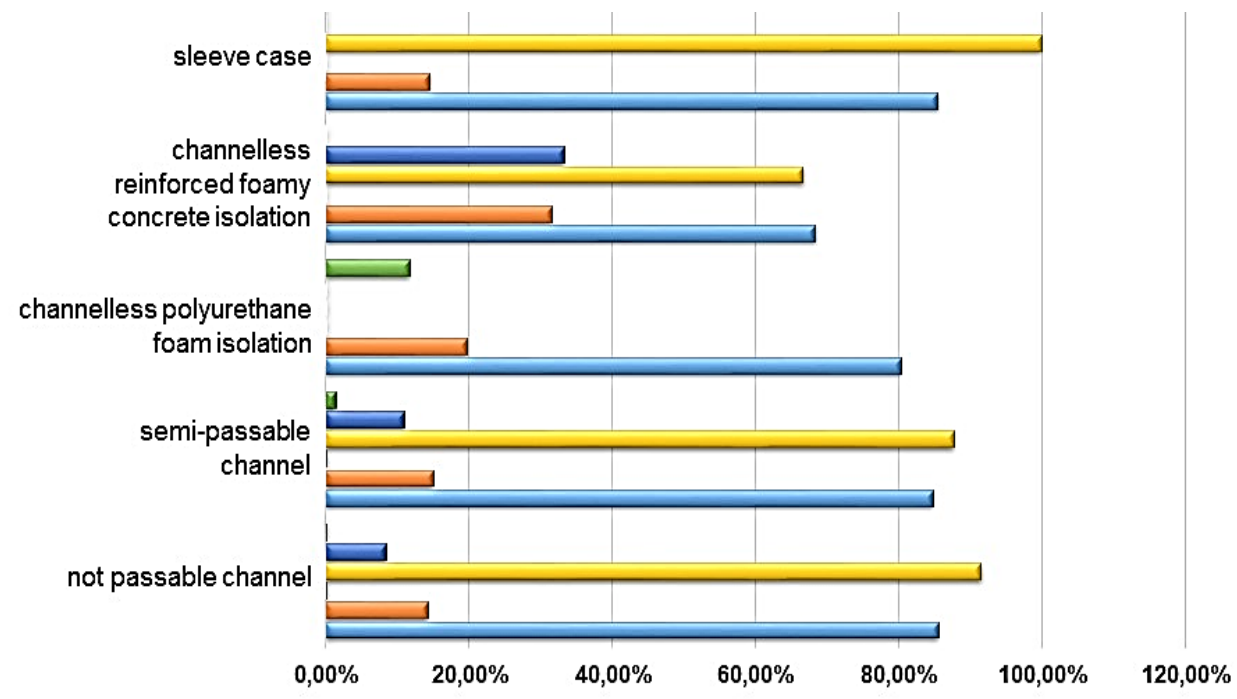

Fig. 2. Distribution of the consequences of the corrosion reasons of changes of technical conditions of the heating systems, which need to be revealed by the diagnostics methods during the monitoring.

Practically for all the types of constructive decisions the excess by 2 or 3 times of the quantity of two types of the events, changing technical condition of the heating systems, owing to corrosion: 1) emergence of fistulas and 2) the emergence of ruptures of structures is observed. Therefore first of all the fistulas and ruptures of corrosion origin have to become the "target" objects of identification during diagnostics in modern HSO. At the same time the used methods of obtaining information, including technical methods, have to be optimized for ensuring their maximum informational content for decision-making in the system of ecological management.

That is obvious that the choice of objects of diagnostics (sites of the heating systems) has to be carried out based on formation of priority from the point of view of the potential environmental risks, following the corrosion defects, which have arisen during the use of engineering system. For the defects which are previously estimated as single we suggest to consider the analytical approach, used in foreign practice of diagnosing, offered by American Society of Mechanical Engineers (ASME), specializing in technical standards (Estimated Repair Factor, ERF) [13]. Application of this indicator, which effectiveness was confirmed in practice, has a certain technological restriction (the reliability of information is provided only in case of assessment of corrosion defects of pipeline wall, which are in the interval of $10 \ldots 80$ percent from its thickness. Analytically the indicator is calculated as follows:

$$
E R F=\frac{M A O P}{D F P}
$$


$M A O P$ - the maximum admissible operating pressure in the pipes of the heating systems, $\mathrm{MPa}$;

$D F P$ - the destroying pressure, MPa.

The destroying pressure is calculated, depending on the ratio of nominal diameter of the pipeline and the length of the defined corrosion defect, designated as G:

$$
G=0.893 \cdot \frac{L}{\sqrt{D_{a} \cdot S}}
$$

$\mathrm{L}$ - the length of corrosion defect, mm;

$\mathrm{Da}$ - the nominal outer diameter of a pipe, $\mathrm{mm}$.

If $\mathrm{G} \leq 4.0$ :

$$
D F P=p \cdot 1,1 \cdot\left(\frac{1-0,67 \cdot \frac{\mathrm{c}}{S}}{1-0.67 \cdot \frac{\mathrm{c}}{S} \cdot \frac{1}{\sqrt{G^{2}+1}}}\right)
$$

If $\mathrm{G}>4.0$ :

$$
D F P=p \cdot 1,1 \cdot\left(1-\frac{\mathrm{c}}{S}\right)
$$

$\mathrm{p}$ - internal excessive pressure in the pipeline, $\mathrm{MPa}$;

$\mathrm{c}$ - depth of the corrosion defect, $\mathrm{mm}$;

$\mathrm{S}$ - nominal thickness of the pipe wall, $\mathrm{mm}$.

The volume of ERF indicator, obtained analytically, can be interpreted according to its volumes. We will also note certain differences in assessment of environmental risks and preventive measures in $\mathrm{HSO}$, aimed at their localization. If $\mathrm{ERF}<0.9$, The defective site causes the minimum environmental risks, therefore management of HSO can make the decision on continuation of maintenance of the estimated section of the pipeline without any decrease in operating pressure and without any actions for the defects elimination. Subsequent control of speed of processes of corrosion on the analysed site is also necessary. If $E R F \geq 1.0$, the analysed site of the heating system bears great environmental risks, therefore management of HSO has to make the decision on carrying out some unplanned repair work of certain types, aimed on the revealed defects elimination. Problematic decisions are made if $0.9 \leq \mathrm{ERF}<1.0$. That means, that the analysed site of the heating system is potentially dangerous from the point of view of environmental risks, at the same time management of HSO can make the decision on continuation of maintenance of the heating system without any decrease in operating pressure but with obligatory elimination of corrosion defects within the scheduled repair. This approach to the determination of the priority of corrosion defects with their conditional division according to the degree of environmental risks can be used as the first stage of diagnosing. However, in practice, when factors of technological, economic, organizational character interfere with the implementation of requirements of further safe operation of the site of the heating system, according to the calculated ERF are possible. In this case management in HSO for providing greater guarantees of ecological safety of the heating systems under maintenance can carry out calculating-and-experimental works on specification of assessment of current condition of the analysed site with corrosion defects, having organized some target actions for diagnostics of the condition of the heating system by technical means.

Despite the existence of an insignificant share of the not corrosion causes of the change of technical condition of the heating systems (up to $10 \%$ of total), it is impossible to exclude 
them from the consideration from the point of view of possible environmental risks. In this regard, the analysis has been detailed, its results are presented in Figure 3.
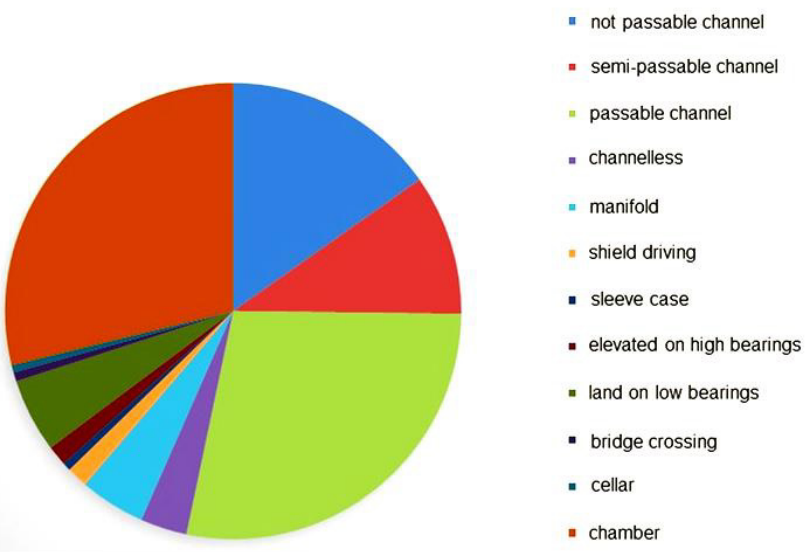

Fig. 3. Distribution of consequences of not corrosion changes of technical conditions of the heating systems according to their structural elements.

The carried-out analysis of certain types of not corrosion consequences of changes of technical conditions of the heating systems according to separate types of elements of engineering systems of various constructive decisions at this stage of consideration of the matter of the improvement of diagnostics and monitoring in HSO, has allowed to reveal two groups of the consequences connected with the adverse environmental impact, identified variously: both during planned surveys (regulated maintenance) and by purposeful application of methods of diagnostics (table 1).

Table 1. Ways of identification of not corrosion changes of technical conditions of the heating systems, influencing the environment.

\begin{tabular}{|c|c|}
\hline \multicolumn{2}{|c|}{ Ways of identification } \\
\hline $\begin{array}{l}\text { 1) revealed during planned surveys and } \\
\text { maintenance }\end{array}$ & 2) revealed by diagnostics methods \\
\hline $\begin{array}{l}\text { malfunction of an element with leakage of the heat } \\
\text { carrier }\end{array}$ & rupture of a welded seam \\
\hline $\begin{array}{l}\text { malfunction of an element without leakage of the } \\
\text { heat carrier }\end{array}$ & through crack of a welded seam \\
\hline $\begin{array}{l}\text { depressurization of omental consolidation or } \\
\text { threaded connection }\end{array}$ & fistula owing to defect of welding \\
\hline separation of the omental compensator & $\begin{array}{l}\text { mechanical deformation of a pipe without } \\
\text { leakage of the heat carrier }\end{array}$ \\
\hline $\begin{array}{l}\text { separation of the omental compensator } \\
\text { rupture of the threaded connection }\end{array}$ & $\begin{array}{l}\text { mechanical deformation of a pipe with the advent } \\
\text { of leakage of the heat carrier }\end{array}$ \\
\hline the other visualized violations of eleme & defect of metal of a pipe \\
\hline
\end{tabular}

List of consequences, provided in table is not closed, according to the authors, we allow its expansion, specification and other types of changes in the development of methods of diagnostics in certain HSO. In this research another task (allocation among not corrosion reasons of changes of technical conditions of the heating systems) of those types which the consequences of impact on the environment are dangerous and concerning which diagnostics methods have to be defined by the technical means along with others, connected with the considered corrosion reasons has been carried out. Synthesis of the results data, obtained during the research of the reasons, causing emergence of environmental risks of the heating systems results in the need of formation of provisions, concerning the terms of diagnostics 
and conditions of its carrying out in the sake of the improvement of these processes. The frequency of holding planned actions for the control of technical condition of the heating systems, while the unplanned actions for diagnostics necessary for specification of information for the implementation of ecological management are held in the mode "Manual control" is rather well known and fulfilled in practice in the Russian HSO. According to the authors, in the core of the choice of terms of performing diagnostics of certain sites of the heating systems, there has to be a comparison of frequency of appearance of defects (vi), the environmental risks, and the importance of possible losses in connection with their realization according to the negative scenario $\left(\Delta L_{i}\right)$. The frequency of refusals $v_{i}$ The size of frequency of defects $v_{\text {_ }}$ i can be determined on a basis of monitoring data by the statistical method, and on the basis of the technical diagnostics of the heating system. The frequency of refusals $v_{i}(t)$ can be calculated as follows can be calculated as follows:

$$
v_{i}(t)=\lim _{\Delta t \rightarrow 0} \frac{M\left\{r_{i}(t+\Delta t)-r_{i}(t)\right\}}{\Delta t}
$$

$\mathrm{M}$ - population mean;

ri $(t)$ - the quantity of defects of the heating system of the $i_{\text {th }}$ type on the analyzed site, causing the environmental risks, which have come from some initial time point till the achievement of the operating time $t$.

According to the experimental data, the authors offered to allocate three group of sites of the heating systems, depending on the causes of defects

According to the experimental data, the authors offered to allocate three groups, harmonized with the systematization of the corrosion reasons, according to the ERF indicator (table 2). The given values of intervals can be specified for a certain HSO, the quantity of intervals and corresponding types of managerial decisions can be increased, depending on the organization policy in the field of ecological safety.

Table 2. Group of sites of the heating systems depending on the quantity of defects.

\begin{tabular}{|c|c|l|}
\hline $\begin{array}{c}\text { Level of the } \\
\text { environmental risks }\end{array}$ & $\begin{array}{c}\text { Quantity of defects } \\
\text { on the site (piece } \\
\text { per 1 km in a year }\end{array}$ & \multicolumn{1}{|c|}{ Managerial decisions } \\
\hline $\begin{array}{c}1^{\text {st }} \text { group (minimum } \\
\text { environmental risks) }\end{array}$ & Less than 0.3 & $\begin{array}{l}\text { Continuation of maintenance without holding } \\
\text { any purposeful actions for technical diagnostics }\end{array}$ \\
\hline $\begin{array}{c}2^{\text {nd }} \text { group (medium } \\
\text { environmental risks) }\end{array}$ & $0.3 \ldots 1.0$ & $\begin{array}{l}\text { Continuation of maintenance with obligatory } \\
\text { carrying out selective control according to the } \\
\text { priorities }\end{array}$ \\
\hline $\begin{array}{c}3^{\text {rd }} \text { group (high } \\
\text { environmental risks) }\end{array}$ & More then 1.0 & $\begin{array}{l}\text { Carrying out obligatory purposeful actions for } \\
\text { technical diagnostics }\end{array}$ \\
\hline
\end{tabular}

The importance of possible losses in connection with the realization of environmental risks $\left(\Delta L_{i}\right)$ should be determined by the negative scenario for each of types of defects of the designs of the heating system, leading to the emergence essential from the point of view of impact on the environment of the consequences (such as gaps, fistulas), based on the cost estimates of separate types of losses of HSO. Their analysis has allowed creating a certain list of types of the losses, gathered into three groups.

1st group (ecological, connected with the violation of ecological safety requirements)

- compensation of ecological damage $\left(L_{1}\right)$,

$$
L_{1}=\operatorname{Sec} \mathrm{p}+\mathrm{S} \mathrm{ec} \mathrm{cw}+\mathrm{Sec} \text { thp }
$$


$\mathrm{S}$ ec $\mathrm{p}$ - the amount of payments and penalties, because of the negative impact on the environment;

$\mathrm{S} \mathrm{ec} \mathrm{cw}$ - the cost of the works, performed for the elimination of the ecological dangerous consequences, which are carried out by the HSO (by its own forces);

Sec thp - the cost of services of the third-party organizations, which are carried out due to the need of the elimination of ecological dangerous consequences for the environment.

- completion of losses of the heat carrier $\left(\Delta L_{2}\right)$ in case of the excess of volume of losses of the heat carrier over the planned volume of issue to consumers:

$$
\Delta L_{2}=\sum_{j=1}^{k} \Delta G_{m / \mathrm{H} j} \cdot c_{j}
$$

$\Delta \mathrm{Gm} / \mathrm{nj}$ - the heat carrier volume, calculated separately for each type, lost due to the excess of volumes comparing with the planned volume of issue to consumers (tons);

$c_{j}$ - the current tariff for a separate type of the heat carrier (roubles per 1 ton);

$\Delta \mathrm{Gm} / \mathrm{n}=\mathrm{Gn} . \mathrm{a}-\mathrm{Gj}$

Gn.a - the actual losses of the heat carrier in case of the violation in the heating system maintenance, causing the negative impact on the environment (tons).

2nd group (compensation of damages to the third parties and losses from short deliveries) - social damage $\left(L_{3}\right)$, expenses for the compensation, which consist of the payments which are carried out by $\mathrm{T}$ the HSO in case of adverse environmental impacts or other types of negative consequences, arising because of violations in work of heating systems;

- compensations according to claims $\left(L_{4}\right)$, consisting of compensations to consumers, owing to blackout or restrictions in the conditions of heat supply, determined according to the provisions of the signed contracts between the HSO and consumers according to the current legislation:

$$
L_{4}=\Sigma \mathrm{Smi}
$$

where Smi is the amount of payment, which is the subject to payment of ith to the consumer of heat for blackouts or restrictions in the conditions of heat supply and the decrease in parameters of the heat carrier;

- underissue of heat $\left(\boldsymbol{L}_{\mathbf{5}}\right)$, estimated on the basis of calculation of the missed benefits because of the underissue of heat and/or the underissue of heat carrier:

$$
L_{5}=P_{m 1}+P_{m 2}
$$

where $P_{m 1}-$ losses from undertransfer of heat to consumers;

$P_{m 2}-$ losses from undertransfer of the heat carrier.

$$
P_{m 1}=\sum_{i=1}^{n} \Delta Q_{i} \cdot\left(P_{t / e i}-P_{c}\right)
$$

where $\Delta Q_{i}$ - underissue of heat according to certain types of the heat carrier, thousand Gcal;

$T_{m / e i}$ - the current tariffs for heat according to certain types of the heat carrier, roubles per 1 Gcal;

$T_{\text {topl }}$ - the current tariffs for heat, roubles per $1 \mathrm{Gcal}$;

$$
P_{m 2}=\sum_{j=1}^{k} G_{j} \cdot\left(P_{t / n j}-P_{t}\right)
$$


where $\mathrm{Gj}$ - underissue of the heat carrier of the proper type, tons;

$P_{t / n j}$ - the current tariff for the proper type of the heat carrier (roubles per 1 ton);

$P_{t}-$ the current tariff for the proper type of the heat carrier (roubles per 1 ton);

3rd group (repair works and other actions)

- effect of the shift of terms of works in case of their earlier completion, i.e. the difference between the cost of unplanned repair work on mitigation of consequences of violations in operation of the heating system and the cost of their scheduled repair $\left(\Delta L_{6}\right)$ :

$$
\Delta L_{6}=\Delta \mathrm{Sr}+\Delta \mathrm{Sm}+\Delta \mathrm{Sa}+\Delta \mathrm{So}
$$

$\Delta \mathrm{Sr}$ - difference between the cost of the repair works, including works on dismantling and construction, works on restoration of the heating system structure, which are carried out by the HSO independently;

$\Delta \mathrm{Sm}$ - difference of the cost of all the types of material resources of the rescue and recovery operations performed by the HSO independently;

$\Delta \mathrm{Sa}$ - the difference of cost of adjustment works, including costs of works on tests and adjusting, bringing the technological mode of operation of the heating system to the required parameters;

$\Delta$ So - the difference according to other items of the expenses, connected with carrying out repair works.

- other expenses $\left(L_{7}\right)$ including expenses on implementation of actions for establishment of circumstances of approach of environmental risks on the certain site of the heating system as a part of the economy of HSO, conducting claim activities and other types of organizational works.

In general, the equation for calculation of the importance of possible losses in connection with environmental risks according to the negative scenario $\left(\Delta L_{i}\right)$, taking into account the provided list of types of the losses, united into three groups, is the following:

$$
\Delta L_{i}=\left(\Delta L_{1}+L_{2}\right)+\left(L_{3}+L_{4}+L_{5}\right)+\left(\Delta L_{6}+L_{7}\right)
$$

The use of two indicators $\left(v_{i}\right)$ и $\left(\Delta L_{i}\right)$, connected with the frequency of defects and the cost assessment of their consequences, for making of managerial decisions in the system of ecological management of HSO, aimed at the decrease in the environmental risks is possible thanks to the formation of the integrated indicator I which can be calculated as follows:

$$
I=\sum_{i} v_{i} \cdot \Delta L_{i}
$$

$v_{i}$ - the frequency of defects of the heating system of the $i_{\text {th }}$ type on the analysed site, connected with the environmental risks;

$\Delta L_{i}$ - the importance of possible losses, connected in case of the negative scenario of the impact on the environment, connected with the existence of defects of the heating system of the $i_{\text {th }}$ type on the analysed site.

The greater the value of the indicator I, the more problem is the site of the heating system, from the point of view of environmental risks. In scales of the whole economy of HSO it is possible to point out the priorities in the application of methods of technical diagnostics of the heating system condition, directed to specification of their operational characteristics and receiving necessary for decision-making in the system of ecological management of information. 
Formation of the provisions for the choice of technical methods of diagnostics was not included into problems of the real research. However at this stage of studying of the directions of the improvement of diagnostics, allowing to predict ecological safety of the engineering systems were created, thanks to the obtained quantitative data and priorities revealed at the expense of it, certain requirements to the choice of methods of technical diagnostics of the heating system condition, including:

\section{for the corrosion reasons}

- the methods allowing to fix local thinning of the walls of pipelines in the form of ulcers from external and internal corrosion are most relevant;

- application of the methods, revealing the presence of corrosion factors is necessary (including the presence of water in the channel, the humidity of isolation increased heat losses on the site, presence of "pipe - the earth" electro-potential, sites with the raised tensely deformed state, etc.)

\section{for not corrosion reasons}

- the methods, providing check of the observance of requirements to welded connections of pipelines of the heating systems and revealing defects much less allowed by normative documents [14];

- the methods, defining the existence of violations of compensation of heat expansion of pipes (cracks and ruptures of a welded seam and mechanical deformations of pipes).

Nowadays the considerable arsenal of technical means of diagnostics of the heating systems condition, which are used by the Russian HSO, is already created. The specifics of the Russian heating systems, noted earlier are the high accident rate, promoted emergence of various technical means of diagnostics, which greatly exceed similar developments in other countries, owing to much smaller demand in the conditions of the minimum accident rate of engineering systems. At the same time the variety of constructive decisions of the heating systems under maintenance, demands an individual approach to the choice of the methods of diagnostics, allowing to determine ecological safety of engineering systems, taking into account the design features of the sites, criticality of the predicted and recorded damages and also the cost and reliability of the methods, planned to application.

\section{Discussion}

Having carried out the analysis of the opportunities of the improvement of diagnostics of the heating systems condition in the context of ecological management due to the definition of conditions of application of methods of diagnostics of the heating systems condition, we will turn to the debatable matters of the improvement of monitoring on the basis of information, which has to be created by the results of their application. At the wording of the relevant proposals, the authors recognized, that data representation forms in monitoring in substantial aspect are some type of interface between opportunities of obtaining certain data on the results of application of the methods of diagnostics, which are important for the system of ecological management of $\mathrm{HSO}$, and quantitative and qualitative parameters of heating systems, established according to the requirements of the specifications and technical documents, reflecting their maintenance characteristics, which influence the ecological safety $[15,16,17]$. At the same time the order of execution of documents on the results of diagnostics during the monitoring has to provide the systematization of data of diagnostics for ensuring objectivity and convenience of the subsequent analysis.

That was already noted that monitoring in modern THO has to be focused on providing proper information for the system of ecological management, taking into account the opportunities and the prospects of information technology development, referred to the category of auxiliary technologies. Therefore, all the "output documents" on any applied methods of diagnostics of technical condition of the heating systems, have to be made out 
automatically as result of analytical data processing in the monitoring base. That needs to be provided at a stage of the monitoring creation. However, first of all owing to the lack of requirements on the need of formation on any constant basis of data on operational characteristics of the heating systems in the Russian standard technical documents, in professional community any conventional decision on this matter has not been submitted. In fact, not all the information systems, used in HSO, studied by the authors, can be recognized to be perfect from the point of view of application in the system of ecological management [18].

However, besides the data on operational characteristics of the heating systems during the monitoring in HSO it also is necessary form the group of the indicators, connected with the existence of potential risk of negative impact on the environment, which emergence is caused with some technical condition of the heating systems. In fact, it is offered to add «the ecological block" to the approaches, which are already acquired in practice, without breaking the developed system of monitoring. Information of this block is of the multi-purpose nature for the use in the system of ecological management. It is important for planning of actions for realization of environmental policy and actions for the decrease in environmental risks, calculation of ecological-and-economic indicators on the same basis with the traditional technical and financial-and-economic, making of investment decisions on the basis of diversity of scenarios of development, taking into account some ecological priorities, formation of motivation of personnel for the use of creative potential of each worker in resource-saving and the decrease in the environmental risks and also for immediate informing all the interested parties on the happened accidents, their ecological consequences and actions for their elimination $[19,20]$.

The basic provisions of formation of information on sites of heating systems as a part of monitoring, used in the system of ecological management, have to make up the following system:

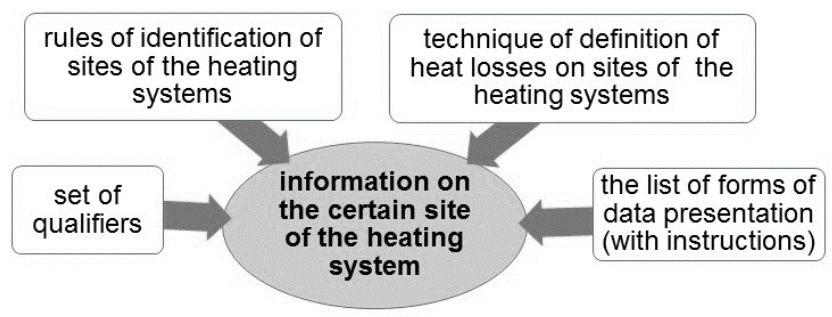

Fig. 4. The basic provisions of formation of information on sites of the heating systems as a part of monitoring, used in the system of ecological management.

Information concerning each site of the heating system, in the volume demanded for management, which quality will conform to requirements of realization of scientific-andtechnological and ecological priorities of the development of the heat-supplying branch has to become the result of application of these provisions in HSO.

\section{Conclusion}

Diagnostics and monitoring of the heating systems condition has great importance for ensuring their reliability, for the increase in profitability and ecological safety of maintenance in the conditions of urban development. The research of the applied approaches and methods at the organization of diagnostics and monitoring in the heat-supplying organizations has proved their insufficient efficiency because of the lack of adequate information for adoption of the managerial decisions allowing to develop multiple scenarios of the development taking 
into account the orientation to ecological safety of engineering systems. Attempts of accounting of ecological-and-economic and nature protection aspects of functioning of the heating systems, imposing new requirements to the choice of methods of diagnostics of technical conditions of the heating systems during the monitoring were not made. The analysis of ten-year statistics of damages of heating systems has allowed to range the most characteristic reasons of changes of technical conditions of heating systems according to their main types and to estimate consequences of the development of these reasons (certain types of damages of structural elements and probability refusals in their work). Methodical provisions according to criticality of the defects of the heating systems under maintenance, influencing the choice of control methods during the diagnosing at dangerous objects, such as heating systems, will allow to estimate the level of the direct and indirect relevant cost and losses, connected with the environmental risks in case of the negative scenario, having determined the importance of costs of compensation of ecological damage, caused by different types of refusals. All these aspects make negative impact on the environment, which makes HSO to form one more contour of management, which is ecological management as a subsystem of management of HSO, functioning in the territory of modern urban development. In modern circumstances that will provide continuous development of both nature protection activity of the organization, and the control system of its activity. The offered mechanisms of improvement of diagnostics and monitoring processes will allow the HSO to increase the efficiency of their activity due to the decrease in losses of heat during its transportation and distribution and to ensure ecological safety of the engineering systems, operated in the urban environment.

\section{References}

1. N. Verstina, A. Goncharov, E. Evseev, Economy: yesterday, today, tomorrow 4, 42-54 (2016)

2. N. Verstina, E. Akimova, T. Blinova, Real estate: economy, management 3, 42-47 (2015)

3. N. Verstina, T. Meshcheryakova, MATEC Web of Conferences 73 (2016)

4. T. Meshcheryakova, N. Verstina, Advances in Intelligent systems and computing 692, 1136-1150 (2018)

5. T. Verminskaya, V. Zinatullin, A. Kuhta, I. Rubtsov, E. Chibisova, Almanac of modern science and education 7, 37-39 (2008)

6. A.A. Krygin, Automatic equipment and telemechanics 9, 83-102 (2010)

7. T. Blinova, MATEC Web of Conferences, 73 (2016)

8. N. Verstina, E. Evseev, Advances in Intelligent systems and computing 692, 1125-1135 (2018)

9. R. Dylewski, J. Adamczyk, Energy and Buildings 54, 88-95 (2012)

10. A. Skvortsov, S. Slyusarenko, S. Subbotin, V. Dmitriyenko, A. Kobrin, Information support of engineering systems (2018) https://elibrary.ru/item.asp? id=22426691///

11. E. Gumerova, O. Gamayunova, T. Meshcheryakova, Advances in Intelligent Systems and Computing 692, 432-439 (2018)

12. M. Tyre, RES POLICY 20-1, 57-76 (1991)

13. E. Vasilyeva, IOP (Earth and Environmental Science) 90, 12216 (2017)

14. A. Mottaeva, A. Minnullina, IOP Conference Series: Earth and Environmental Science 90(1), 012123 (2017) 
15. M.A. Bahauovna, M.A. Bahauovna, International Journal of Applied Engineering Research 10(23), 43446-43449 (2015)

16. A. Mottaeva, J. Ćetković, Advances in Intelligent Systems and Computing 692, 11511159 (2018)

17. N. Verstina, T. Meshcheryakova, Biosciences biotechnology research Asia 12(2), 14111423 (2015)

18. E. Chibisova, T. Meshcheriakova, Krasnoyarie Science 6 2-2, 146-148 (2017)

19. A. Mottaeva, V. Lukinov, A. Mottayeva, Strategy of management of the state and municipal ownership: theory and practice (MGSU, Moscow, 2015)

20. T. Meshcheriakova, MATEC 106, 06021 (2017) 